\title{
Examination of the Potential for Time Domain Electromagnetic Method for Monitoring Infiltration and Recharge in Arid Areas
}

\author{
Hesham El-Kaliouby, Ty Ferre ${ }^{1}$ and Ken Zonge ${ }^{2}$ \\ Geophysics Dept., King Abdulaziz University, Saudi Arabia, \\ ${ }^{1}$ Hydrology and Water Resources, University of Arizona, and \\ ${ }^{2}$ Ken Zonge, Zonge Engineering and Research Organization, USA
}

Received: 15/2/2006 Accepted: 26/11/2006

\begin{abstract}
Recharge flux is one of the most difficult components of the water balance to measure. However, quantitative estimates of this flux are critical for water resource planning in semi-arid and arid areas. Geophysical methods that can be operated from the ground surface offer significant advantages for recharge monitoring. Specifically, because they do not require boreholes, they are typically inexpensive and can be used to monitor over large areas. Electrical and electromagnetic geophysical methods may be useful for monitoring recharge because of the dependence of both the electrical conductivity and the dielectric permittivity on the volumetric water content of a porous medium. However, it is unclear whether the pattern of water content change that occurs during recharge can be inferred, uniquely, from all geophysical responses. In this study, we examine the suitability of time domain electromagnetic (TEM) methods for monitoring infiltration into an initially dry soil. This preliminary examination is conducted as a sensitivity analysis in which we vary the porosity $(\mathrm{P})$, initial water content (Wci) and the hydraulic conductivity $(\mathrm{K})$ of the medium and calculate the TEM response with time during an infiltration event. Infiltration into a dry medium causes a large, localized change in the water content, making these conditions most conducive to recharge monitoring with geophysical methods. We consider this study to be a firstlevel examination of the potential for recharge monitoring with TEM.
\end{abstract}

\section{Introduction}

Knowledge of the rate and patterns of recharge is crucial for water use planning in arid and semi-arid regions. Unfortunately, due to difficulties in measuring 
recharge, which occurs at low rates far below the ground surface, this component of the water budget is commonly poorly quantified. In this study, we investigated the potential of a noninvasive, geophysical method, time domain electromagnetics (TEM), to quantify recharge rates. We chose, as a first step, to study recharge beneath ephemeral streams for two reasons. First, for many semi-arid environments, this focused recharge contributes a large fraction of total recharge. Second, infiltration beneath ephemeral streams occurs at the ground surface and involves relatively large changes in volumetric water content, which makes it more amenable to indirect measurement than distributed recharge. As a result, this study can be seen as the first test of the ability of TEM for recharge monitoring.

During infiltration beneath a previously dry ephemeral stream, the volumetric water content of the bed materials and underlying strata can increase dramatically. Therefore, measurements of the volumetric water content profile beneath the stream can be used to constrain unsaturated flow models to determine the rate of infiltration. One property that has been measured commonly to infer water content is electrical resistivity (Hendricx et al. 1992; Sheets and Hendricx, 1995; Yeh et al. 2002). Many geophysical methods have been developed to measure electrical resistivity; each has its own advantages and disadvantages. For water content profiling beneath ephemeral streams, advantageous characteristics include the ability to measure the water content profile rapidly and with high depth resolution with a single instrument placement on the ground surface. TEM has the ability to measure the depth profile, rapidly, with a single placement. However, it is unclear whether the measured profile has sufficient accuracy to constrain flow models.

In this study, we investigate, through coupled forward models of water flow and TEM response, the expected time-varying response of a TEM instrument to infiltration beneath an ephemeral stream bed. Based on these responses, we discuss the probable utility of TEM instruments for monitoring recharge beneath ephemeral streams and in more challenging environments, such as basin floors.

Studying water infiltration in the vadose zone is important because it influences recharge to the underlying aquifer and the transfer of contaminants. Typical hydrological instruments, such as tenisometers and neutron probes, used for vadose zone characterization only give point measurements. It is possible that geophysical measurements could add information to these point measure

The time domain electromagnetic (TEM) induction method is emerging as a leading geophysical technique in hydrogeological studies. A grounded or ungrounded loop of wire is placed on the ground surface to act as a transmitter. 
A second loop is placed either inside the transmitter loop or coincident with it to act as a receiver. The transmitter loop is energized with pulses of alternating positive and negative polarity to induce a transient EM field within the subsurface. For TEM methods, the voltage induced in the receiver loop is measured as a function of time while the transmitter is off. Later time measurements are associated with greater sampling depths, allowing for depth profiling of electrical properties. These properties can then be used to infer the water content profile. Because TEM methods do not require measurements of small secondary fields in the presence of a large transmitted primary field, they offer more efficient broadband data collection and, in many instances, simpler data inversion than frequency domain EM methods. TEM data have been used widely for groundwater studies [e.g. Everett and Meju,, 2005; El-Kaliouby, 1995, 2001]. However, there are no published reports of TEM being used to measure transient subsurface water movement.

\section{Data Acquisition and Modeling}

A central loop TEM configuration is modeled where the transmitter loop is square, $40 \mathrm{~m}$ on a side. The receiver loop is square, $10 \mathrm{~m}$ on a side. For this preliminary analysis, we take a simplified approach to represent infiltration beneath an ephemeral stream. Specifically, we assume that the subsurface is homogeneous and that the water content is spatially uniform and low before the onset of infiltration. Infiltration is modeled as a one dimensional, vertical process. This mimics the response at the center of a large ephemeral stream, far removed from the effects of lateral flow at the edges of the stream. We assume that the wetting front is sharp and that the water content is a spatially uniform and high between the ground surface and the wetting front. Finally, we assume that infiltration occurs at a constant flux that is equal to the hydraulic conductivity of the medium, which gives rise to a water content above the wetting front that is equal to the porosity and a constant wetting front velocity for the conditions described. In this way, we can model the subsurface water content distribution as a time varying series of two-layer models. The upper layer has higher water content than the lower. The thickness of the upper layer is the product of the wetting front velocity and the elapsed time since the onset of infiltration. Twelve earth models are formed by varying the porosity $\left(0.16,0.25\right.$, or $0.45 \mathrm{~m}^{3}$ / $\left.\mathrm{m}^{3}\right)$, initial water content before infiltration $\left(0.05\right.$ or $\left.0.10 \mathrm{~m}^{3} / \mathrm{m}^{3}\right)$, and the hydraulic conductivity $(0.03$, or $0.3 \mathrm{~m} / \mathrm{h})$. The earth models considered are listed in Table 1.

With these simplifying assumptions, the depth of wetting front with time, $\mathrm{Z}$ (t), can be calculated as:

$$
\mathrm{Z}(\mathrm{t})=(\mathrm{K} * \mathrm{t}) /(\mathrm{P}-\mathrm{Wci})
$$


Table 1. Earth models examined for different initial and saturated water contents and hydraulic conductivities.

\begin{tabular}{|c|c|c|}
\hline $\begin{array}{c}\text { Saturated water content } \\
(\mathbf{P})\end{array}$ & $\begin{array}{c}\text { Initial water content } \\
\text { (Wci) }\end{array}$ & $\begin{array}{c}\text { Hydraulic conductivity } \\
\text { (K) } \mathbf{~ m} / \mathbf{h}\end{array}$ \\
\hline 0.45 & 0.05 & 0.3 \\
\hline 0.45 & 0.1 & 0.3 \\
\hline 0.25 & 0.05 & 0.3 \\
\hline 0.25 & 0.1 & 0.3 \\
\hline 0.16 & 0.05 & 0.3 \\
\hline 0.16 & 0.1 & 0.3 \\
\hline 0.45 & 0.05 & 0.03 \\
\hline 0.45 & 0.1 & 0.03 \\
\hline 0.25 & 0.05 & 0.03 \\
\hline 0.25 & 0.1 & 0.03 \\
\hline 0.16 & 0.05 & 0.03 \\
\hline 0.16 & 0.1 & 0.03 \\
\hline
\end{tabular}

Where

$\mathrm{t}=$ Infiltration time calculated at: $0,0.1,0.5,1,2$ days.

$\mathrm{K}=$ Hydraulic conductivity $[\mathrm{m} / \mathrm{h}]$.

$\mathrm{P}=$ Saturated water content $\left[\mathrm{m}^{3} / \mathrm{m}^{3}\right]$.

Wci $=$ Initial water content $\left[\mathrm{m}^{3} / \mathrm{m}^{3}\right]$.

The purpose of this investigation is to examine the sensitivity of the TEM response to broad changes in subsurface conditions during infiltration. The simple infiltration model used here produces simple, layered structures, which are amenable to TEM modeling, but allows for flexibility in the subsurface response. For example, as $\mathrm{K}$ increases, the velocity of the wetting front increases and hence the thickness of the saturated layer increases for a given elapsed time of infiltration. As the difference between the initial and saturated water content (P-Wci) decreases, the velocity of the wetting front increases with an associated change in water contents of the layer(s). We examined eleven earth models, as shown in Table 1.

For each elapsed time, the water content is converted to an electrical resistivity based on the measured data of Sternberg and Levitskaya (2001) in which they measured the electrical conductivity for soil sample with different water contents (0.06-0.45) as shown in Fig. 1. Based on this relationship, the electrical conductivity for water contents of $0.45,0.25,0.16,0.1$ and 0.05 are $0.085,0.09$, $0.045,0.015$ and $0.005 \mathrm{~S} / \mathrm{m}$, respectively. 


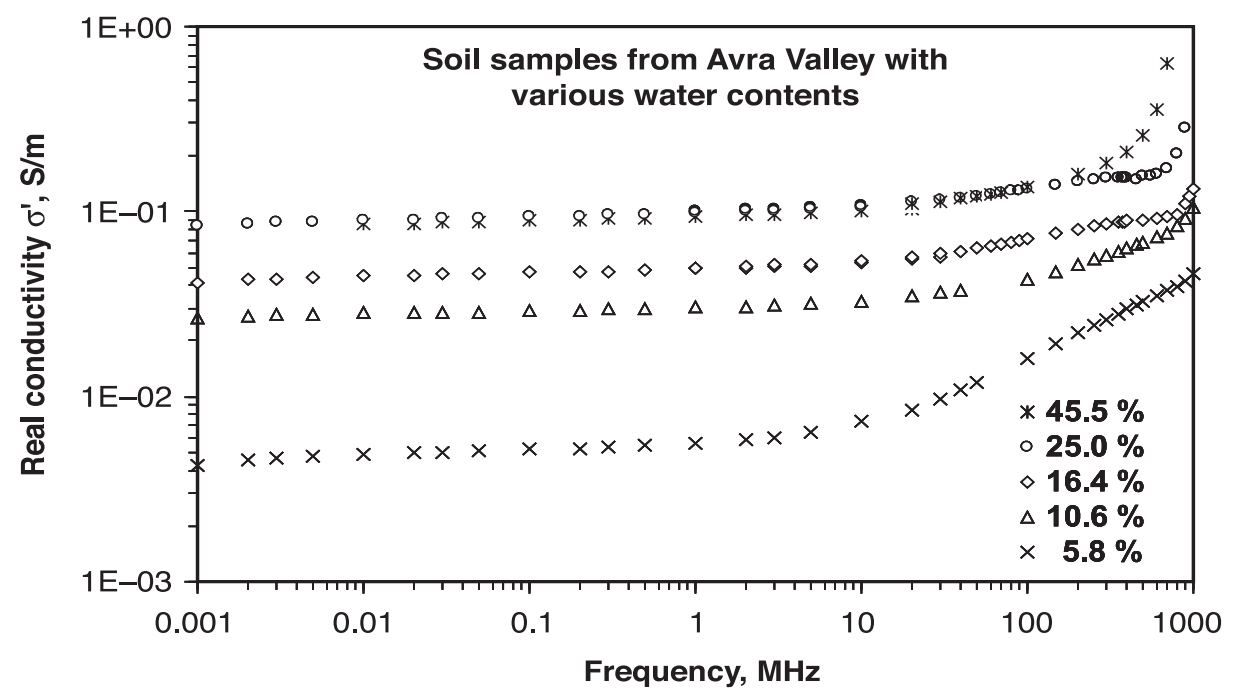

Fig. 1. Electrical conductivity for soil samples from Avra Valley versus frequency with different water contents (Sternberg and Levitskaya, 2001).

Further, we examined these measured data to check if it follows Archie's law (Archie, 1942). We found that with the exception of the 0.45 water content, the electrical conductivity is related to the water content by the following Archie's equation (Berg, 1995; Hagrey, 2004):

$$
\sigma=1.335 \theta^{1.93}
$$

If we take the 0.45 water content into account, then we get another equation that is less accurate than equation (4) but applies for all levels of saturation.

$$
\sigma=0.45 \theta^{1.44}
$$

\section{TEM Response to Uniform Half Spaces}

TEM instruments provide measurements of voltage as a function of time after a signal is applied to the subsurface. Figure 2 shows the TEM response for spatially uniform water content conditions, as would occur at 0 days, before infiltration. Water contents of $0.05,0.1,0.16,0.25$ or 0.45 are shown.

The initial water content (Wci) in the lower half-space affects the magnitude of the TEM response. The figure shows the effect of Wci with all other parameters held constant. It will be most useful to monitor the changes in TEM response from the background condition to minimize the effects of differences in the initial conditions.

During early time of infiltration, there are differences among the TEM responses. Some cases lead to a peak response that decays rapidly at later times 


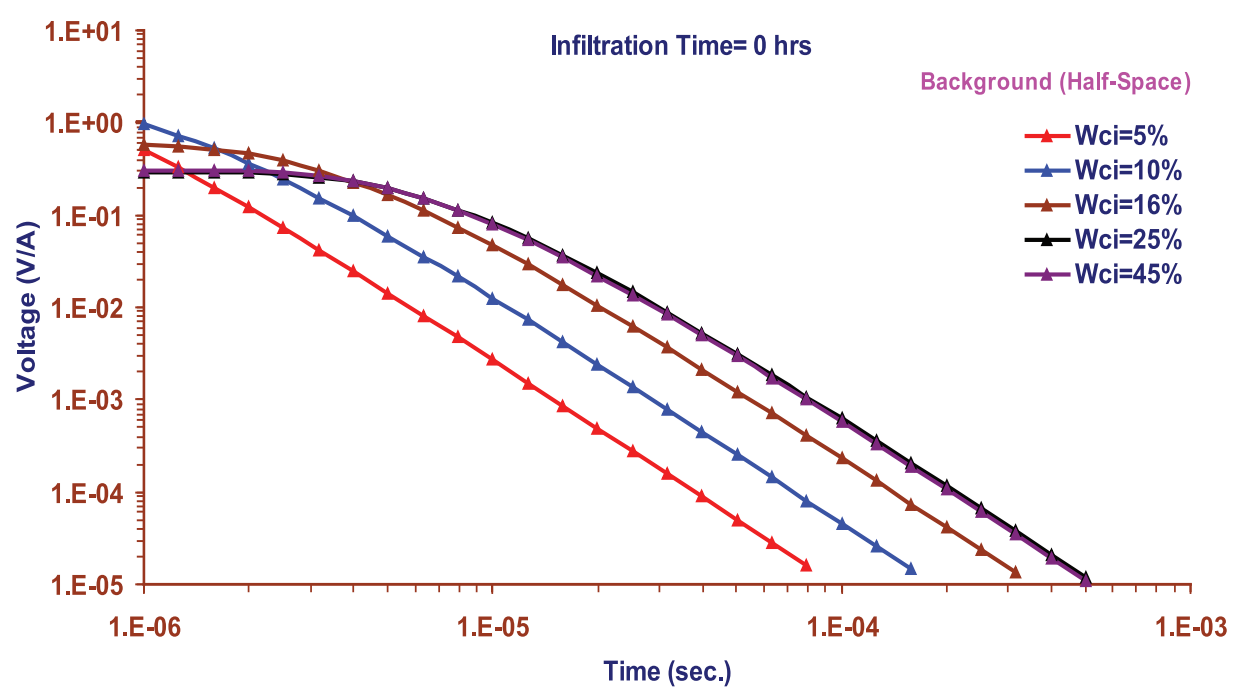

Fig. 2. Calculated TEM central loop response of rectangular loop $(40 \mathrm{~m} \times 40 \mathrm{~m})$ simulating the background response ( 0 days) of initial volumetric water content (Wci) for 0.05 , $0.1,0.16,0.25$ and 0.45 before infiltration.

(Fig. 3). This peak appears because early time TEM voltage response is proportional to the resistivity of the shallow layer; which changes from the conductive upper layer to the resistive deeper region. This peak decreases with continued infiltration as the thickness of the first layer increases and the early TEM response is dominated by the uppermost conductive layer (Spies and Frischknecht 1991, p. 316).

\section{Variation of TEM Response with Infiltration Time}

Figure 3 shows an example of a calculated TEM response for a soil with the following properties: $\mathrm{P}=0.25$; $\mathrm{Wci}=0.1$; and $\mathrm{K}=0.3$. Figure 4 shows the TEM responses for the same conditions, except that $\mathrm{K}$ has been decreased to 0.03 . For large $K(0.3 \mathrm{~m} / \mathrm{h})$, which could represent the case of sand, the TEM response changes much faster with time of infiltration due to the fast advance of the wetting front with depth (Fig. 3). While for small $\mathrm{K}(0.03 \mathrm{~m} / \mathrm{h})$, which could represent the case of loam or silt, we can notice the TEM response changes slowly with time of infiltration due to the slow advance of the wetting front with depth (Fig. 4).

The low K soil produces relatively small changes from the background condition with voltages that converge to a common value at late time; this response is due to the relatively shallow advance of the wetting front during the monitoring period. In contrast, the high $\mathrm{K}$ medium gives rise to highly curved responses that 


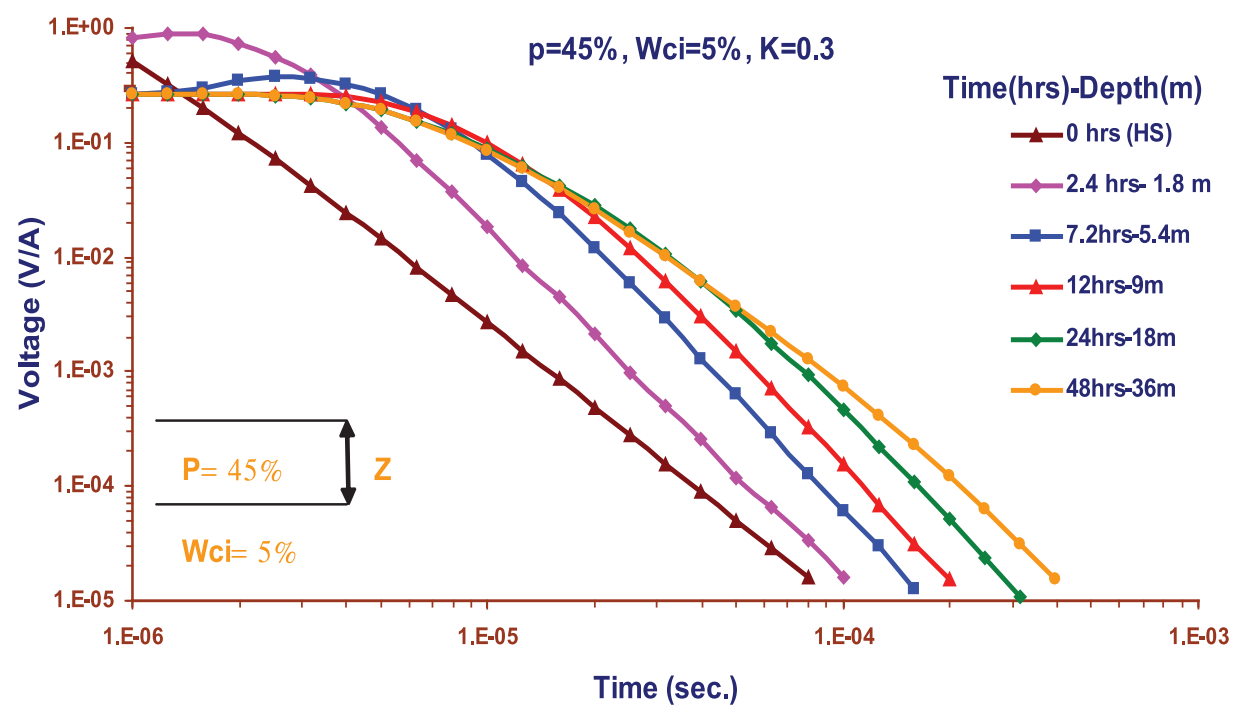

Fig. 3. Calculated TEM response for the case of $(p=0.45, \mathrm{Wci}=0.05, \mathrm{~K}=0.03)$ with the change of time of infiltration from (0-2 days).

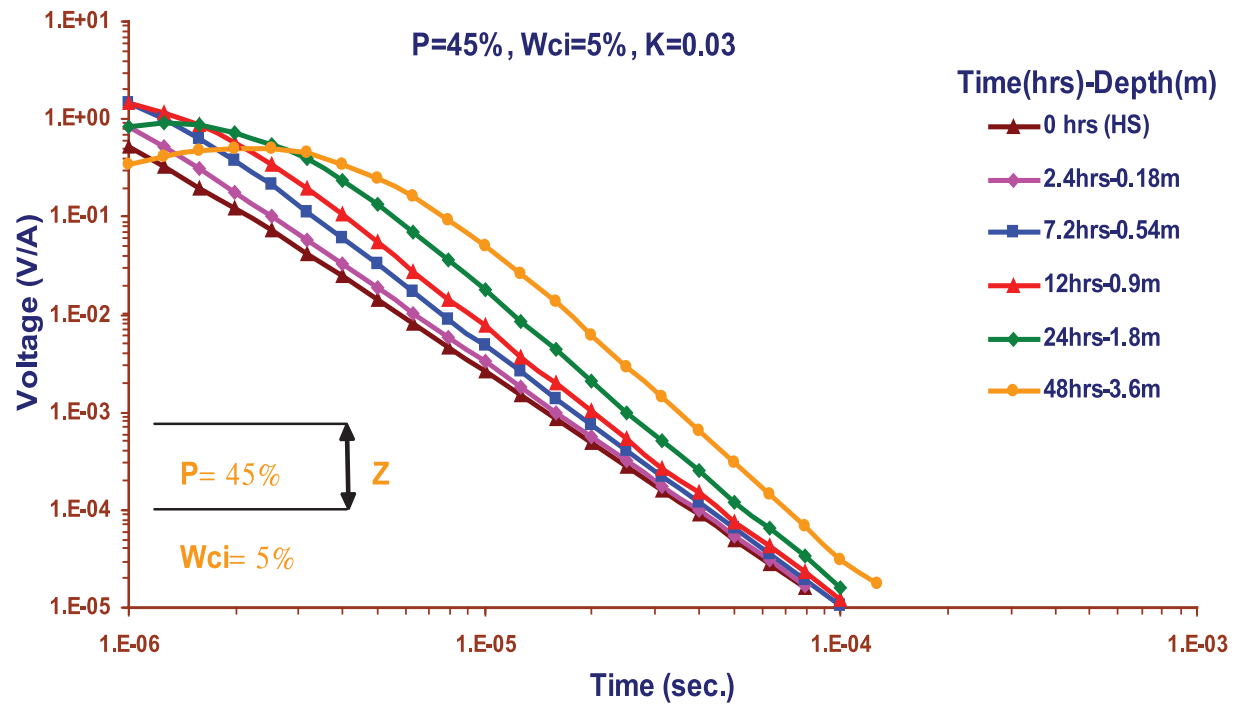

Fig. 4. Calculated TEM response for the case of $(p=0.45$, Wci $=0.05, K=0.3)$ with the change of time of infiltration from (0-2 days). 
diverge at late time with increased time of infiltration. These responses indicate that the TEM response could be used to infer the depth of the wetting front and, therefore, the hydraulic conductivity for the boundary conditions imposed here.

\section{Effects of Soil Properties on TEM Responses During Infiltration}

Figures $5 \mathrm{a}, \mathrm{b}, \mathrm{c}$ and $\mathrm{d}$ show the TEM response after $(0.1,0.5,1,2$ days) of elapsed times of infiltration for the low $\mathrm{K}$ medium $(\mathrm{K}=0.03)$. Figures $6 \mathrm{a}, \mathrm{b}, \mathrm{c}$ and $\mathrm{d}$ show the TEM response after $(0.1,0.5,1,2$ days) of elapsed times of infiltration for the high $\mathrm{K}$ medium $(\mathrm{K}=0.3)$. The initial water content (Wci) has an effect on the magnitude of the TEM response especially for small $\mathrm{K}$. This effect increases at early elapsed times of infiltration (0.1-0.5 days) because the thickness of the saturated layer is still small.

The hydraulic conductivity (K) has an important effect on the magnitude of the TEM response because it determines the depth of wetting front with time (thickness of first saturated layer).

For small $\mathrm{K}$, there is little effect of $\mathrm{P}$ and a clear effect of Wci, mainly at early elapsed time of infiltration. As the time of infiltration increases, the upper layer occupies more of the sample volume of the instrument, so there is greater sensitivity to $\mathrm{P}$.

For large $\mathrm{K}$, the effect of $\mathrm{P}$ is higher than Wci especially at late time of infiltration.

We can only see the effect of Wci in the late TEM response where the effect of the lower half-space (Wci) is dominant. This is clear especially at early infiltration time where water did not penetrate to deeper layers and it disappears at late infiltration time where water reaches deep layers.

\section{Comparison with Measured Data}

An infiltration experiment at the Central Avra Valley Storage and Recovery Project (CAVSRP) was conducted. CAVSRP is a property of the city of Tucson, Arizona, USA where there are many, 20-acre basins that have been in operation in Avra Valley since late 1997.

The purpose of the geophysical investigation was to monitor water infiltration into the aquifer. This recharge basin provides controlled conditions for effective comparative-analysis of data yielded through hydrogeophysical fieldbased investigations where sensors can be deployed for extended time periods.

The goal of this survey is to improve our understanding of the application of the transient electromagnetic method and to determine its limitations for monitoring applications. 


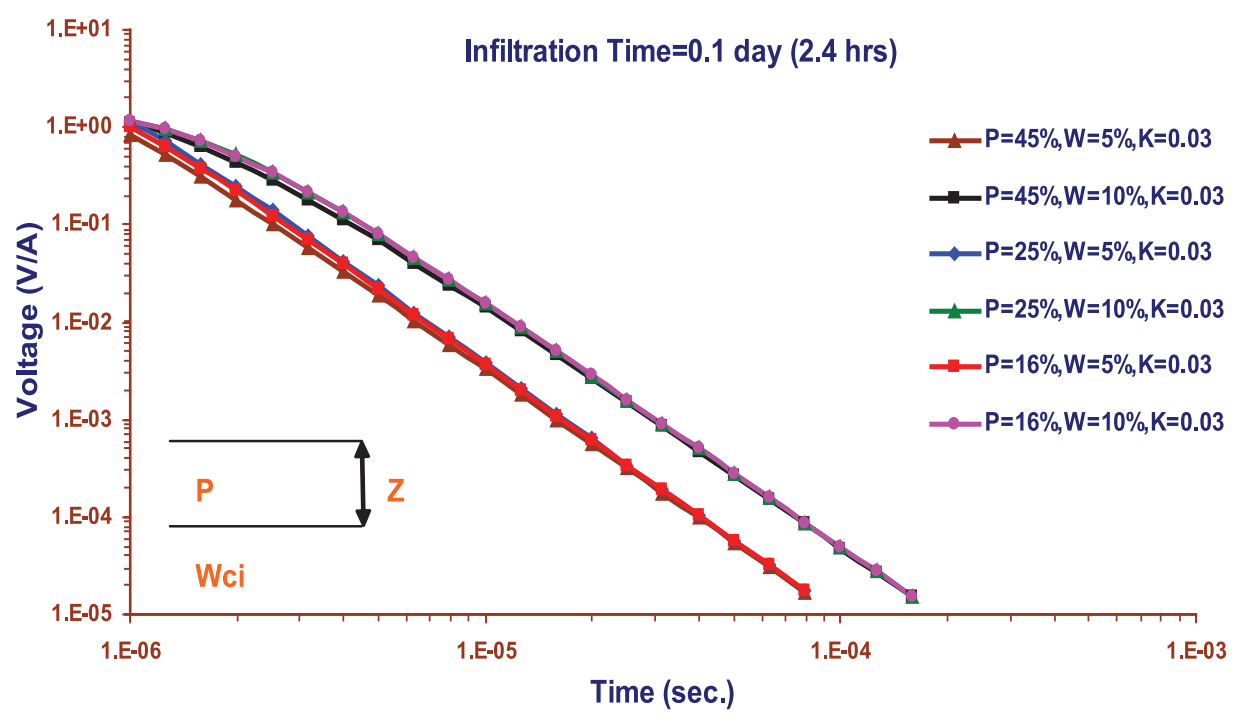

Fig. 5(a). Calculated TEM response after $2.4 \mathrm{~h}(0.1$ days) of infiltration with $K=0.03$.

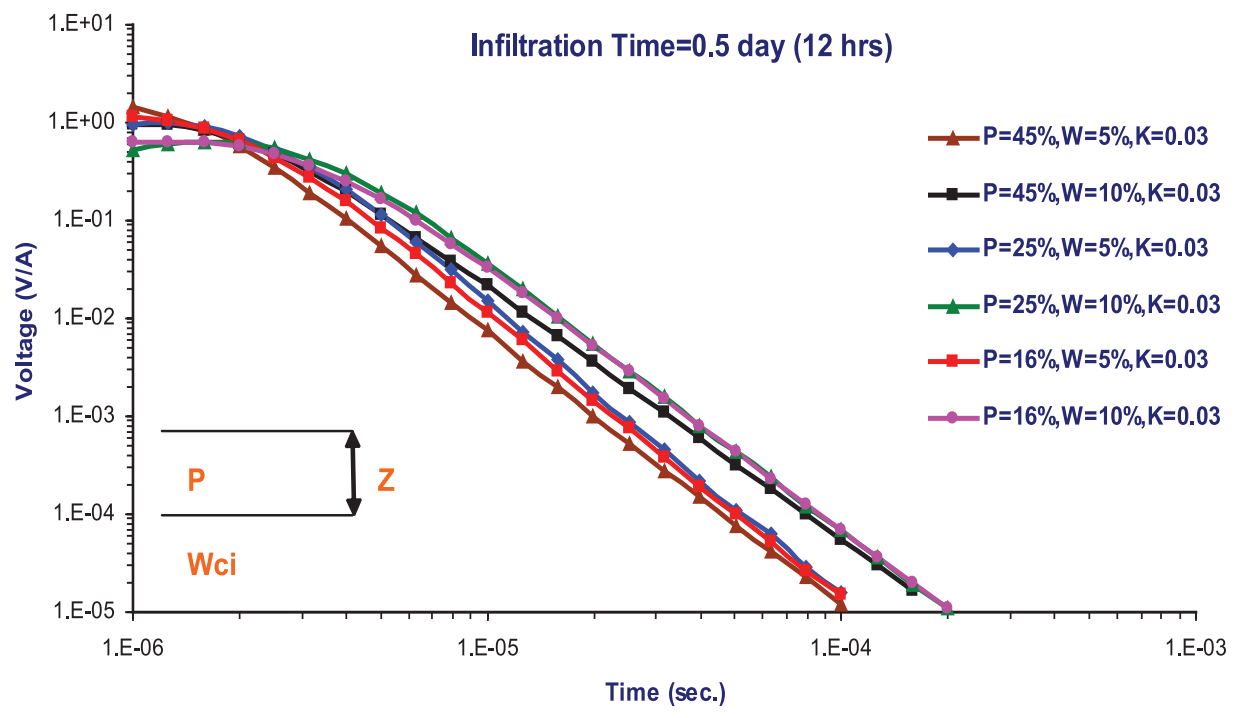

Fig. 5(b). Calculated TEM response after $9.6 \mathrm{~h}(0.5$ days) of infiltration with $K=0.03$. 


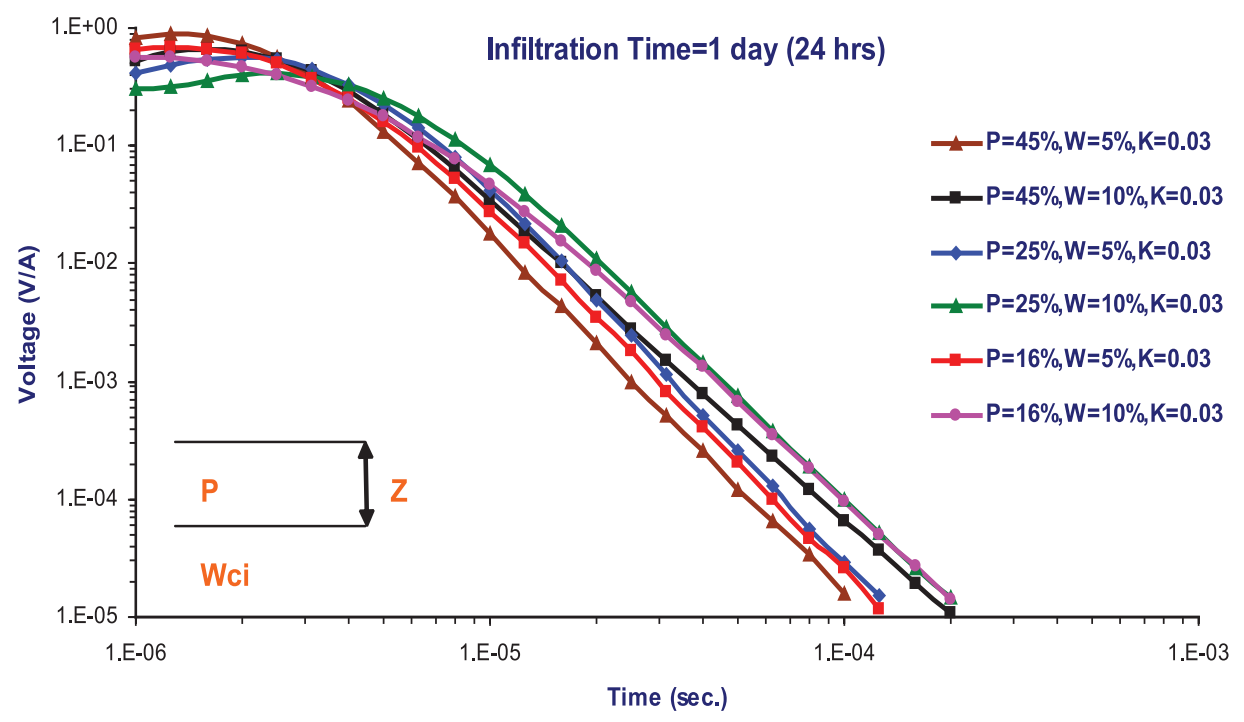

Fig. 5(c). Calculated TEM response after 24 h (1 day) of infiltration with $K=0.03$.

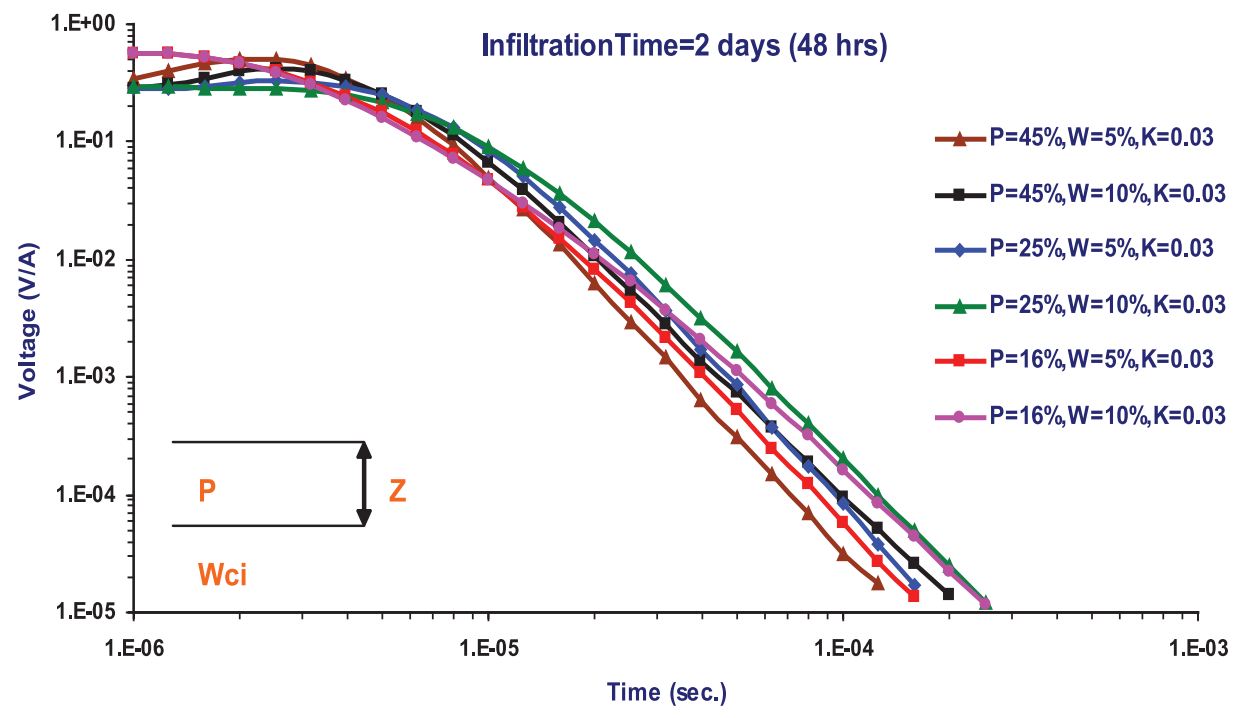

Fig. 5(d). Calculated TEM response after $48 \mathrm{~h}$ ( 2 days) of infiltration with $K=0.03$. 


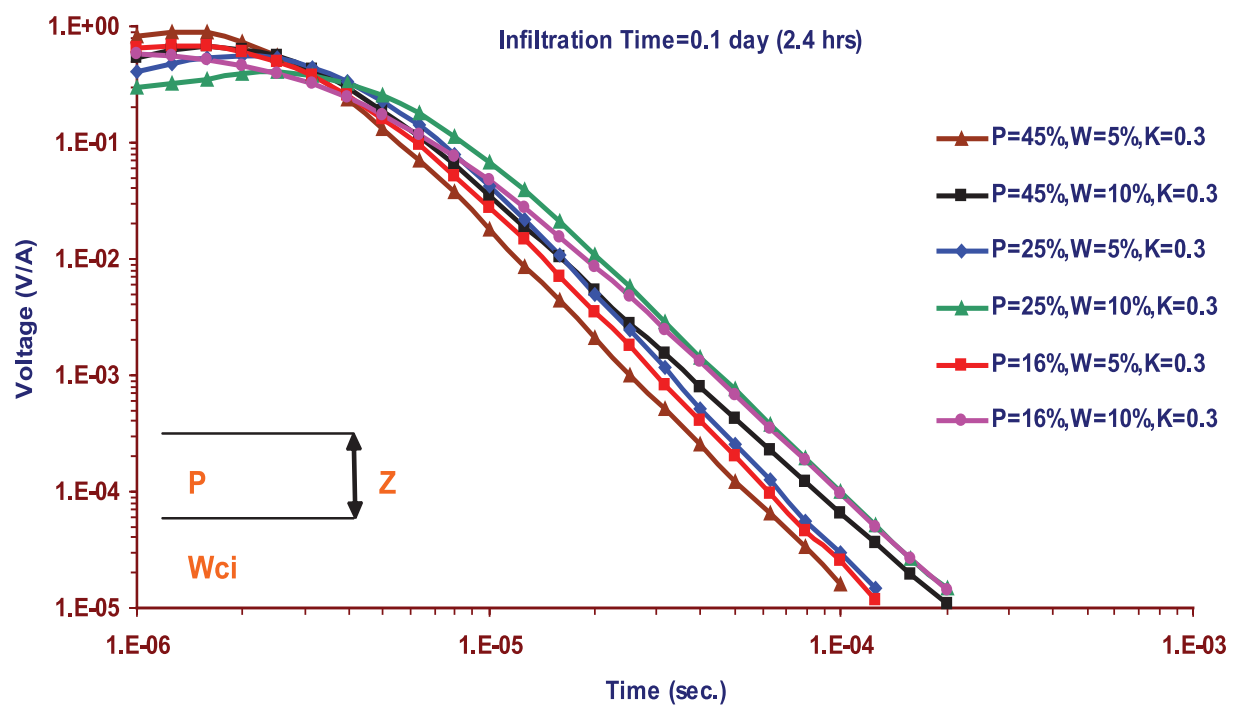

Fig. 6(a). Calculated TEM response after $2.4 \mathrm{~h}(0.1$ days) of infiltration with $\mathrm{K}=0.3$.

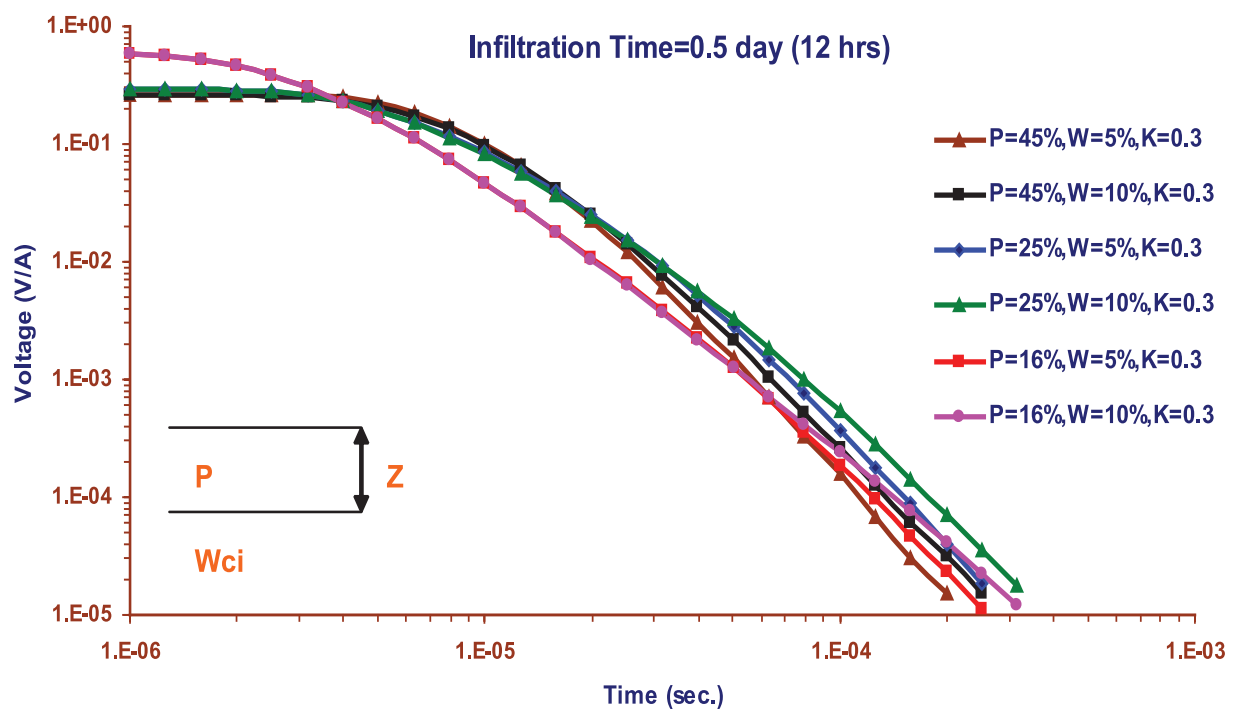

Fig. 6(b). Calculated TEM response after12 h (0.5 days) of infiltration $K=0.3$. 


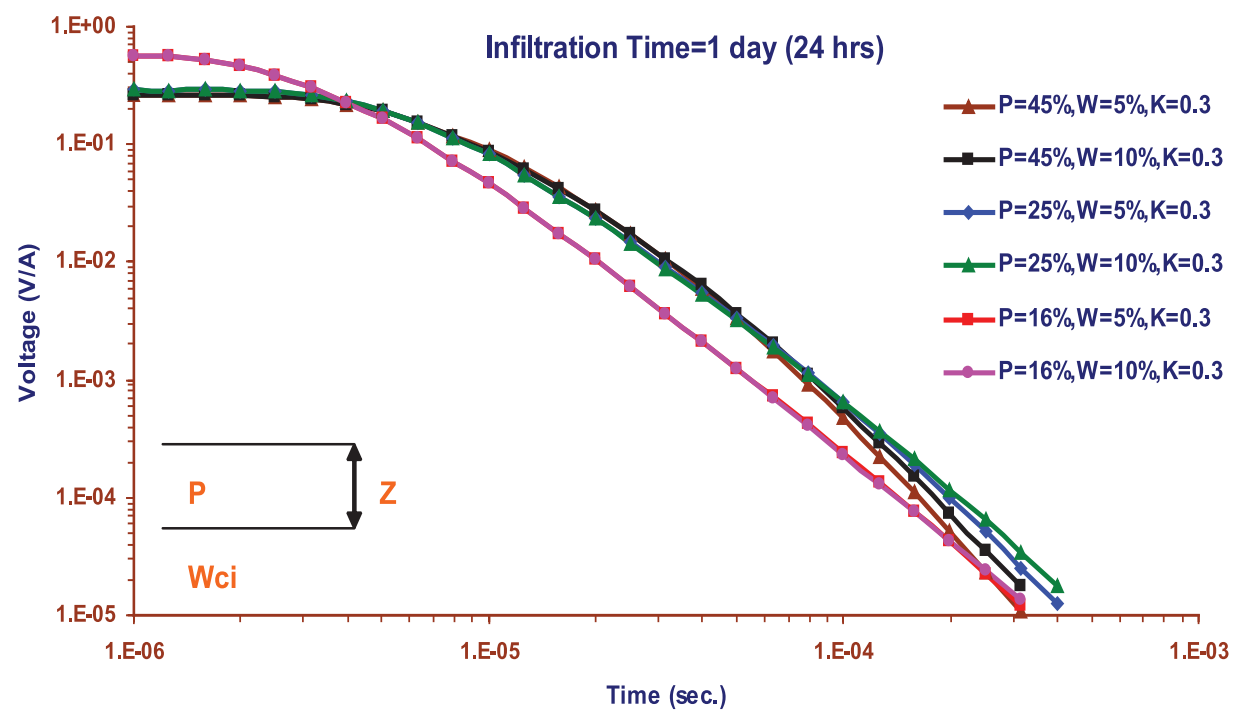

Fig. 6(c). Calculated TEM response after $24 \mathrm{~h}$ (1 day) of infiltration with $K=0.3$.

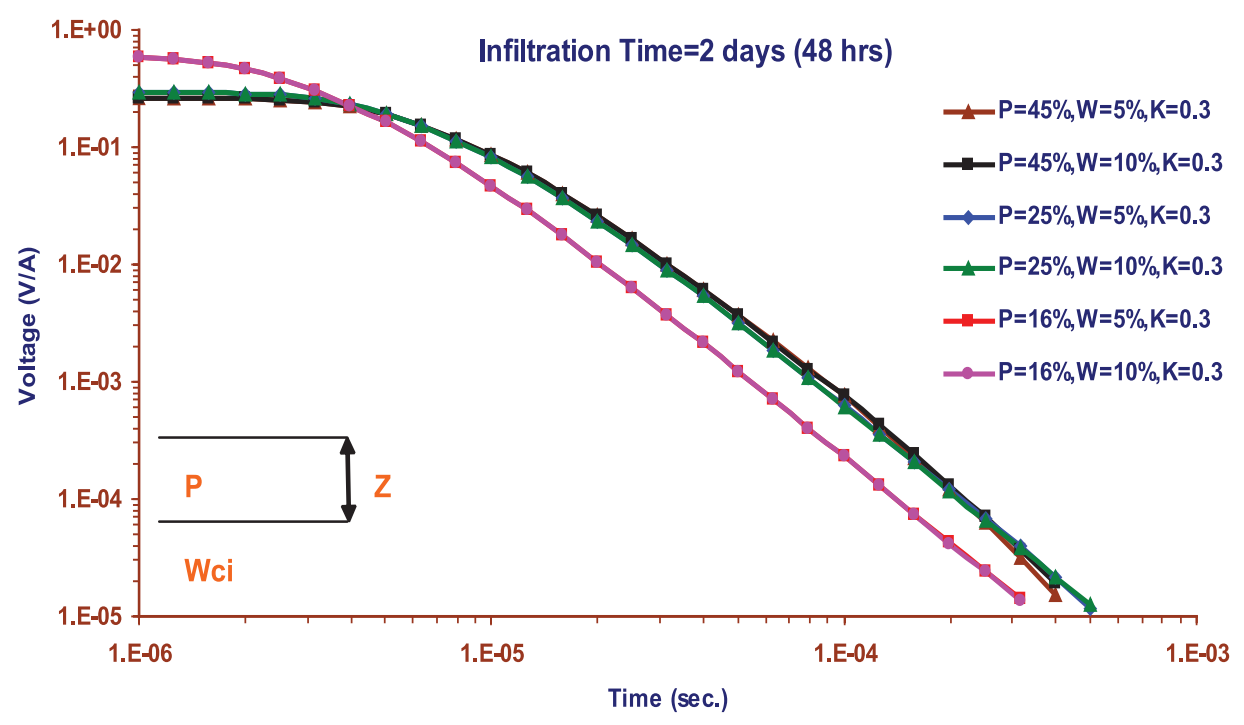

Fig. 6(d). Calculated TEM response after $48 \mathrm{~h}$ ( 2 days) of infiltration with $\mathrm{K}=0.3$. 
Four TEM antennas were set up. Three of them were placed inside the infiltration basins and one reference station was placed outside of the basins. The Zonge Engineering NanoTEM system was used to monitor daily changes in the subsurface electrical properties following flow events. The NanoTEM system makes rapid, early time measurements of the decaying electromagnetic field. These high frequency responses are necessary to provide high-resolution measurements of water content in the upper 30 meters of the vadose zone.

Figure 7 shows the measured TEM data at Tucson Basin 107 measured at station 2 located at the northern part of the pond for the period from June 2-27, 2003. Similar data was recorded at station 3 (Fig. 8) at the southern part of the pond for the same period of time.

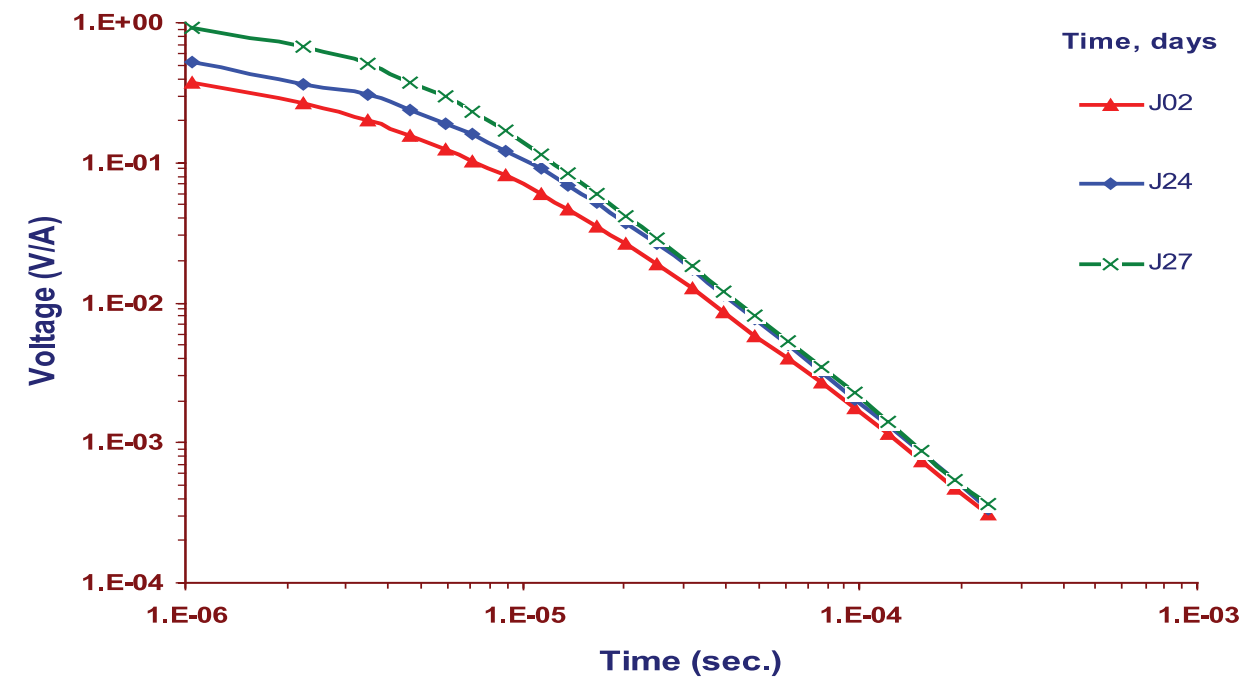

Fig. 7. Measured TEM data at Tucson Basin 107 (Station 2) inside the pond. J02 shows the background data before infiltration and $\mathrm{J} 24$ and $\mathrm{J} 27$ shows the response after drainage of water from the surface into the ground.

Measurements at June 2 represent the background water distribution before infiltration while June 24-27 represents the response after drainage of water from the surface into the ground. Comparing the models of the different hydraulic conductivities (Fig. 6,7) with the field data measured, we can notice that the trend of this field data represents a case of small K (Fig. 4) and that the wetting front depth was very shallow since all the TEM response tends or converges to the background (Wci) similar to the case of Fig. 4. This may be attributed to lateral flow of the water in relict channels rather than strictly downward flow. This conclusion is consistent with changes in the TEM measurements made at the reference station outside the infiltration basin (Fig. 9). 


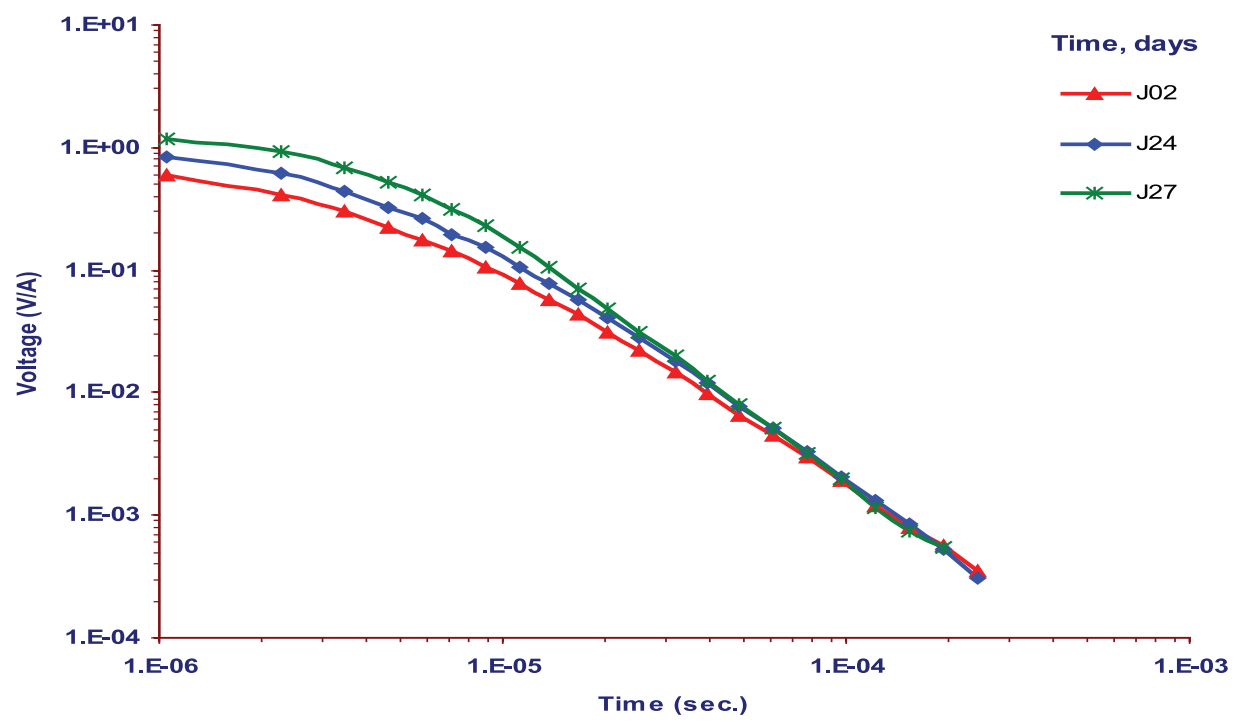

Fig. 8. Measured TEM data at Tucson Basin 107 (Station 3) inside the pond. J02 shows the background data before infiltration and $\mathrm{J} 24$ and $\mathrm{J} 27$ shows the response after drainage of water from the surface into the ground.

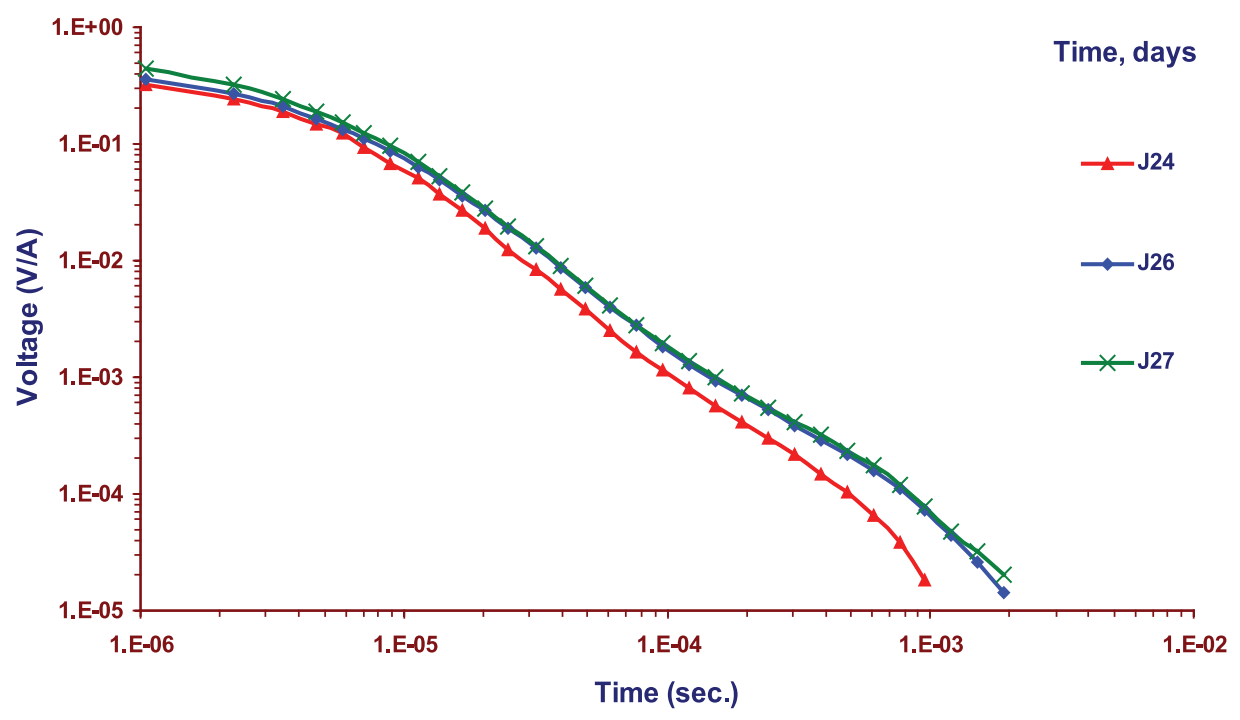

Fig. 9. Measured TEM data at Tucson Basin 107 (Station 4) outside the pond to the West side. J24 to J27 shows the response after drainage of water from the surface into the ground suggesting lateral movement of the infiltrated water to the west side of the pond rather than downward movement. 


\section{Conclusion}

Transient electromagnetic induction monitoring showed some promise for time-lapse monitoring of water infiltration. A sensitivity analysis suggests that the method may be able to detect changes during infiltration. These changes appear to be particularly sensitive to hydraulic conductivity, for the flow conditions considered. However, it is still unclear whether the data have sufficient information to constrain quantitative analyses of infiltration beneath ephemeral streams.

\section{References}

Archie, G.E. (1942) The electrical resistivity log as an aid in determining some reservoir characteristics, Trans. AIME, 146: 54-62.

Berg, C. (1995) A simple effective-medium model for water saturation in porous rocks, Geophysics, 60 (4): 1070-1080.

El-Kaliouby, H. (1995) An Induced Polarization Study Using Transient Electromagnetic Method on Subsurface Sedimentary Layers, M.Sc. Thesis, Cairo University, Cairo, Egypt.

El-Kaliouby, H. (2001) Induced Electrical Polarization in Geophysical Prospecting for Economic Minerals, Ph.D. Thesis, Cairo University, Cairo, Egypt.

Everett, M and Meju, M. (2005) Near surface controlled source electromagnetic induction. in: Hydrogeophysics, Y. Rubin and S. Hubbard (Eds.), Springer.

Hagrey, S. Meissner, R. Werban, U. Rabbel, W. and Ismaeil (2004) A. Hydro, Bio-geophysics, The Leading Edge, : 670-674.

Hendricx, J., Baerends, B., Raza, Z. and Sadiq, M. and Akram, M. (1992) Soil salinity assessment by electromagnetic induction of irrigated land, Soil Sci. Am. J., 56: 1933-1941.

Sheets, K. and Hendricx, J. (1995) Noninvasive soil water content measurement using electromagnetic induction, Water Resources Research, 31: 2401-2409.

Spies, B. and Frischknecht, F. (1991) Electromagnetic Sounding, Chapter 5, in: Electromagnetic Methods in Applied Geophysics, Vol. 2, M. Nabighian, (Ed.), SEG Publications.

Sternberg, B. and Levitskaya, T. (2001) Electrical parameters of soils in the frequency range from $1 \mathrm{kHz}$ to $1 \mathrm{GHz}$, using lumped-circuit methods, Radio Science, 36 (4): 709-720.

Yeh, J., Liu, S., Glass, R., Baker, K., Brainard, J., Alumbaugh, D. and LaBrecque, D. (2002) A geostatistically based inverse model for electrical resistivity surveys and its applications to vadose zone hydrology, Water Resources Research, 38: 1278-1291. 


\section{دراسة استخدام الطرق الكهرومغنطيسية في النطاق الزمني لمتابعة تسرب وتغذية المياه في المناطق الجافة}

هشام محمد القليوبي ، و تاي فيري* ، و كِن زونج

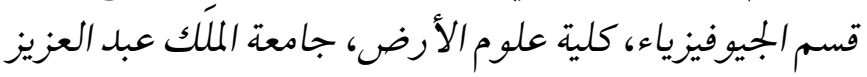

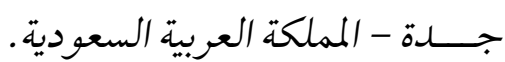
* جامعة أريزونا، الولايات المتحدة الأمريكية.

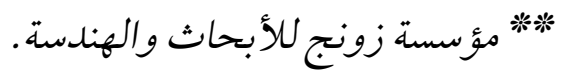

المستخلص. إن عملية تغذية المياه هي من أهم مركبات حساب وقياس ميزانية المياه لتخطيط مصادر المياه في المناطق الصحر اوية. إن الطرق الجليوفيزيقية السطحية لها عدة ميزات لمر اقبة تغذية المياه،

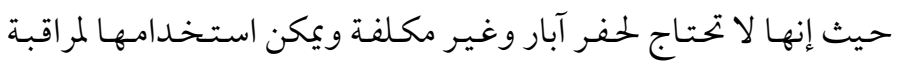

$$
\text { مساحات واسعة. }
$$

يكن استخدام الطرق الكهربائية والكهرومغنطيسية لمتابعة تصريف

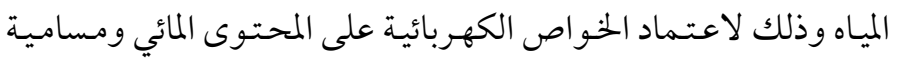

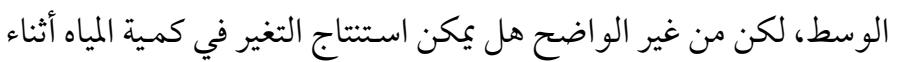
تصريف المياه من القياسات الجيوفيزيقية فقط أم لا؟

في هذه الدراسة قمنا بدراسة مدى كفاية الطرق الكهرومغنطيسية في

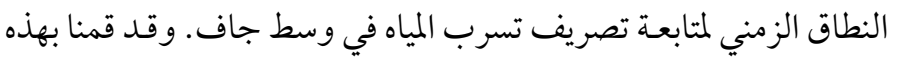

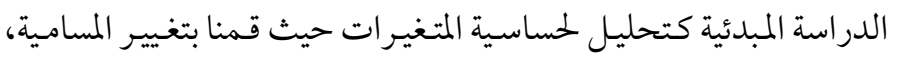

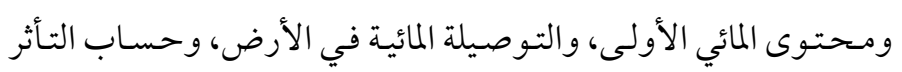

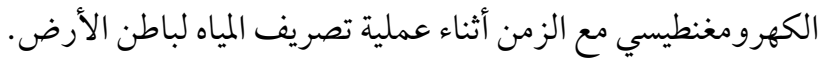
إن عملية تصريف المياه في وسط جاف يؤدي إلى تغيرات كبيرة في

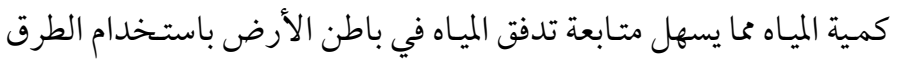

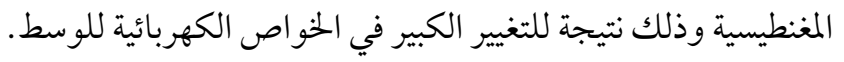


نحن نعتبـر هذه الدراسـة مرحلة أولى لدراسـة مـدى إمكانية استخـدام

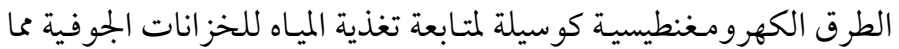

$$
\text { يفتح الباب لدراسات أخرى في هذه المجال. }
$$

